\title{
Short communication: Inhibition of DNA methyltransferase and histone deacetylase increases $\beta$-defensin expression but not the effects of lipopolysaccharide or 1,25-dihydroxyvitamin $\mathrm{D}_{3}$ in bovine mammary epithelial cells
}

\author{
Mercedes F. Kweh, ${ }^{1}$ Kathryn E. Merriman, ${ }^{1}$ and Corwin D. Nelson ${ }^{2 *}$ \\ ${ }^{1}$ Animal Molecular and Cellular Biology Graduate Program, University of Florida, Gainesville 32611 \\ ${ }^{2}$ Department of Animal Sciences, University of Florida, Gainesville 32611
}

\section{ABSTRACT}

Antimicrobial peptides are a common defense against bacterial infections in many species and a significant part of the innate immune response of the bovine mammary gland. The objective of this study was to investigate the influence of epigenetic factors on vitamin $\mathrm{D}$ and toll-like receptor-mediated induction of $\beta$-defensins in mammary epithelial cells. Primary bovine mammary epithelial cells were treated with lipopolysaccharide (LPS, 0 or $100 \mathrm{ng} / \mathrm{mL}$ ), 1,25-dihydroxyvitamin $\mathrm{D}_{3}$ $\left[1,25(\mathrm{OH})_{2} \mathrm{D}_{3}, 0\right.$ or $\left.10 \mathrm{nM}\right]$, and 5-aza-2'-deoxycytidine (5-Aza, inhibitor of DNA methyltransferase, 0 or $5 \mu M$ ) or trichostatin A (TSA, inhibitor of histone deacetylase, 0 or $80 \mathrm{n} M$ ) in a factorial arrangement. Effects of treatments on $\beta$-defensin gene expression along with genes for cytokines and enzymes known to be induced by LPS or $1,25(\mathrm{OH})_{2} \mathrm{D}_{3}$ were evaluated by quantitative PCR. The LPS treatment induced expression of $\beta$-defensin (DEFB)3, DEFB5, DEFB $7, D E F B 10$, enteric $\beta$-defensin $(E B D)$, lingual antimicrobial peptide $(L A P)$, and tracheal antimicrobial peptide $(T A P)$; whereas, the $1,25(\mathrm{OH})_{2} \mathrm{D}_{3}$ treatment increased DEFB5 and $D E F B 7$ expression and decreased $L A P$. The 5 -Aza treatment increased expression of DEFB3, DEFB5, $D E F B 10, E B D, L A P$, and $T A P$ in the presence and absence of LPS. The TSA treatment increased expression of DEFB3, DEFB4,DEFB5,DEFB , and DEFB10 in the absence of LPS but decreased LPS-induced expression of and $L A P$ and TAP. Together these results indicate that $\beta$-defensin expression in bovine mammary epithelial cells is likely influenced by DNA methylation and histone acetylation. Investigation of environmental and nutritional factors that influence epigenetic control

Received December 10, 2018.

Accepted February 12, 2019

*Corresponding author: cdnelson@ufl.edu of $\beta$-defensins in the mammary gland may be beneficial for improving resistance to intramammary infections. Key words: mammary immunity, $\beta$-defensin, chromatin remodeling, lipopolysaccharide, vitamin D

\section{Short Communication}

Defensins are a class of small, cationic antimicrobial peptides that provide innate defense against bacterial infections in animals (Ganz, 2003). The amphipathic and cationic nature of defensins results in direct bactericidal activity by disruption of bacterial membranes (Meade et al., 2014). Defensins also contribute to host defense as immunomodulatory molecules, for example, by stimulating chemotaxis (Mackenzie-Dyck et al., 2011). The bovine neutrophil $\beta$-defensins 1-13 (BNBD1-13, also referred to as DEFB1-13), enteric $\beta$-defensin (EBD), lingual antimicrobial peptide (LAP), and tracheal antimicrobial peptide (TAP) are encoded by a cluster of genes with high sequence similarity and proximity located on bovine chromosome 27 (Diamond et al., 1991; Selsted et al., 1993; Schonwetter et al., 1995). This group of $\beta$-defensins has potent bactericidal activity and represents a significant component of the bovine innate immune response. In the bovine udder, for example, several $\beta$-defensins are highly upregulated during mastitis caused by bacterial (Roosen et al., 2004; Swanson et al., 2004) or endotoxin challenge (Isobe et al., 2009; Merriman et al., 2018).

Induction of defensin expression primarily occurs via a well-conserved toll-like receptor (TLR)-nuclear factor $\kappa \mathrm{B}(\mathbf{N F}-\kappa \mathbf{B})$ pathway. Yang et al. (2006) and Liu et al. (2011) showed that TLR induction of DEFB5 and $L A P$ in mammary epithelial cells (MEC) is mediated by $\mathrm{NF}-\kappa \mathrm{B}$. In addition, the active vitamin $\mathrm{D}$ hormone, 1,25-dihydroxyvitamin $\mathrm{D}_{3}\left[\mathbf{1 , 2 5}(\mathbf{O H})_{2} \mathrm{D}_{3}\right]$, increased DEFB3, DEFB 4, DEFB \%, and DEFB10 in bovine monocytes but not neutrophils (Merriman et al., 2015). Téllez-Pérez et al. (2012) also reported that 
vitamin D increased DEFB10 and $L A P$ in bovine MEC, and Alva-Murillo et al. (2015) showed that butyrate stimulated DEFB5, DEFB10, LAP, and TAP in MEC. The ability of stimulatory factors to induce $\beta$-defensins is likely attributable to accessibility of the promoter response elements to transcription factors. Binding of transcription factors such as NF- $\kappa \mathrm{B}$ or the vitamin $\mathrm{D}$ receptor to cognate promoters of target genes depends on the degree to which the chromatin is accessible (Pike and Meyer, 2014). The bovine $\beta$-defensins are likely not under direct control of the vitamin $\mathrm{D}$ receptor, but we hypothesized that inhibition of chromatin remodeling by DNA methylation and histone acetylation would alter the expression of $\beta$-defensin genes in bovine MEC. The objective of this study was to evaluate the effects of inhibitors of DNA methyltransferase and histone deacetylase activities on induction of $\beta$-defensin genes in response to TLR and vitamin $\mathrm{D}$ signaling. For comparison, the effects of DNA methytransferase and histone deacetylase inhibitors on expression of several key cytokines $(C C L 5, I L 1 B, I L 8)$ induced by LPS and genes induced by $1,25(\mathrm{OH})_{2} \mathrm{D}_{3}(C Y P 24 A 1, i N O S$, and $S 100 A 12)$ were also evaluated in MEC. In addition, the effects of inhibitors on TLR and vitamin D signaling were evaluated in bovine dermal fibroblasts as a comparison to MEC. Expression of $\beta$-defensins has not been reported in bovine dermal fibroblasts previously, but the cells do produce cytokines in response to LPS; therefore, we hypothesized that DNA methyltransferase and histone deacetylase inhibitors would affect $\beta$-defensin expression in dermal fibroblasts as in MEC.

Primary MEC were obtained from parenchymal mammary tissue of 3 pregnant nonlactating (250-260 d gestation) Holstein cows at the University of Florida Dairy Unit as previously described (Wohlgemuth et al., 2016) and approved by the University of Florida Institutional Animal Care and Use Committee. Mammary epithelial cell cultures were prepared by enzymatic digestion (400 $\mathrm{U} / \mathrm{mL}$ collagenase III, $100 \mathrm{U} / \mathrm{mL}$ hyaluronidase, and $2 \mathrm{U} / \mathrm{mL}$ DNase; Worthington Biochemical, Lakewood, NJ) as previously described (Merriman et al., 2015). Cells were cultured in T-75 collagen-coated flasks (Fisher Scientific, Waltham, MA) with Dulbecco's modified Eagle's medium (Fisher) containing 10\% fetal bovine serum (Hyclone Laboratories, Logan UT), $1 \%$ antibiotic-antimycotic solution (Hyclone), and 1\% MEC growth supplement (Life Technologies, Grand Island, NY). Cells were cultured to $90 \%$ confluency then removed by trypsin digestion and stored in $10 \%$ dimethyl sulfoxide (Sigma, St. Louis, MO) in liquid nitrogen. Bovine dermal fibroblasts, referred to as fibroblasts from here on, were generously donated by David Kerr (Department of Animal and Veterinary Sciences, University of Vermont) from 6 Holstein cows as previ- ously described (Carroll et al., 2017). Fibroblasts were cultured in RPMI-1640 with $10 \%$ fetal bovine serum and $1 \%$ antibiotic-antimycotic. For both cell types, cells were cultured to confluency then removed by trypsin digestion, diluted to $1 \times 10^{6}$ cells $/ \mathrm{mL}$, and transferred to 24 -well tissue culture plates. The treatments were applied in a factorial arrangement with 2 levels of LPS ( 0 or $100 \mathrm{ng} / \mathrm{mL}), 2$ levels of $1,25(\mathrm{OH})_{2} \mathrm{D}_{3}$ ( 0 or $4 \mathrm{ng} / \mathrm{mL}$ ), and 2 levels of inhibitor [0 or $5 \mu M$-aza$2^{\prime}$-deoxycytidine (5-Aza) or 0 or $80 \mathrm{n} M$ trichostatin A (TSA)]. The LPS (derived from Serratia marcescens), $1,25(\mathrm{OH})_{2} \mathrm{D}_{3}, 5$-Aza, and TSA were purchased from Sigma Aldrich (St. Louis, MO). The 5-Aza treatment was applied to cells when they were seeded into culture plates and replenished at 24 and $72 \mathrm{~h}$ of culture to allow for inhibition of DNA methyltransferase activity during cell division. All other treatments were applied after $72 \mathrm{~h}$ of culture, and cells were cultured for $16 \mathrm{~h}$ in treatments before harvesting for RNA isolation. The experiment was repeated 3 times, using cells derived from different cows for each experiment (1 cow per experiment for MEC and 2 cows per experiment for fibroblasts). Treatments were applied in duplicate for MEC experiments for a total 6 replicates per treatment. The dose and timing of treatments were based on previous reports (Green and Kerr, 2014; Merriman et al., 2015).

Total RNA of cells was isolated using the Direct-zol MiniPrep RNA isolation kit (Zymo Research, Irvine, CA). The absorbances of 260- and 280-nm wavelengths of each sample were measured using a Nanodrop spectrophotometer to determine RNA purity (260/280 ratio $>1.8$ ) and concentration. The RNA was reverse transcribed using the High-Capacity cDNA Reverse Transcription Kit (Life Technologies, Carlsbad, CA) in $20-\mu \mathrm{L}$ reactions. Reactions were incubated at room temperature for $10 \mathrm{~min}$, followed by $2 \mathrm{~h}$ at $37^{\circ} \mathrm{C}$ and 5 min at $85^{\circ} \mathrm{C}$. Quantitative PCR was performed using the CFX96 Touch Real-Time PCR Detection System (Bio-Rad, Hercules, CA) with the following protocol: 1 cycle of $95^{\circ} \mathrm{C}$ for $10 \mathrm{~min}, 40$ cycles of $95^{\circ} \mathrm{C}$ for $15 \mathrm{~s}$, and $60^{\circ} \mathrm{C}$ for $1 \mathrm{~min}$. Gene-specific primers (Supplemental Table S1; https://doi.org/10.3168/jds.2018-16141) were previously validated for efficiency (Merriman et al., 2015). The threshold cycle (Ct) for each gene was normalized to the geometric mean housekeeping genes RPS9, GAPDH, and ACTB. The least squares means of $\triangle \mathrm{Ct}$ values were transformed using the equation $\left(2^{-\Delta \mathrm{Ct}}\right)$ and reported as abundance relative to housekeeping genes (Livak and Schmittgen, 2001).

The experiments were designed as complete randomized design with blocks. Cow, the source of cells, was the blocking factor. Individual cell culture wells to which treatments were applied were considered the experimental unit. The $\Delta \mathrm{Ct}$ values for each gene were 
analyzed by ANOVA using the GLIMMIX procedure of SAS ver. 9.4 (SAS Inc., Cary, NC). Initially, effects of LPS and $1,25(\mathrm{OH})_{2} \mathrm{D}_{3}$ and interactions between LPS and $1,25(\mathrm{OH})_{2} \mathrm{D}_{3}$ in the absence of inhibitors were analyzed with the model $Y_{i j k}=\mu+B_{i}+L_{j}+D_{k}+L_{j} D_{k}+$ $e_{i j k}$, where $Y_{i j k}=$ dependent variable, $\mu=$ overall mean, $B_{i}=$ random effect of block, $L_{j}=$ fixed effect of LPS, $D_{k}=$ fixed effect of $1,25(\mathrm{OH})_{2} \mathrm{D}_{3}$, and $e_{i j k}=$ residual error. The model $Y_{i j k l}=\mu+B_{i}+L_{j}+D_{k}+I_{l}+L_{j} I_{l}+$ $e_{i j k l}$ was used to analyze interactions between LPS and inhibitor (5-Aza or TSA), where $Y_{i j k l}=$ dependent variable, $\mu$ = overall mean, $B_{i}=$ random effect of block, $L_{j}$ $=$ fixed effect of LPS, $D_{k}=$ fixed effect of $1,25(\mathrm{OH})_{2} \mathrm{D}_{3}$, $I_{l}=$ fixed effect of inhibitor, and $e_{i j k l}=$ residual error. The model $Y_{i j k}=\mu+B_{i}+D_{j}+I_{k}+D_{j} I_{k}+e_{i j k}$ was used to analyze interactions between $1,25(\mathrm{OH})_{2} \mathrm{D}_{3}$ and inhibitor, where $Y_{i j k}=$ dependent variable, $\mu=$ overall mean, $B_{i}=$ random effect of block, $D_{j}=$ fixed effect of $1,25(\mathrm{OH})_{2} \mathrm{D}_{3}, I_{k}=$ fixed effect of inhibitor, and $e_{i j k}=$ residual error. Because the effect of LPS on $\beta$-defensin expression was so dominant over $1,25(\mathrm{OH})_{2} \mathrm{D}_{3}$, we excluded data from samples treated with LPS to analyze interactions between $1,25(\mathrm{OH})_{2} \mathrm{D}_{3}$ and inhibitor. We did test the 3 -way interactions between LPS, $1,25(\mathrm{OH})_{2} \mathrm{D}_{3}$, and inhibitor, but it did not result in any outcomes that could not be explained by the 2-way interactions that were tested. Least squares means were computed for each effect or interaction, and the Tukey adjustment was applied to account for multiple comparisons of means.

As previously reported (Merriman et al., 2015), treatment of MEC with LPS increased $(P<0.05)$ expression of all $\beta$-defensin genes tested (DEFB3, DEFB4, DEFB5, DEFB7, DEFB10, EBD, LAP, and TAP; Figure 1A, Supplemental Table S2). The $1,25(\mathrm{OH})_{2} \mathrm{D}_{3}$ treatment increased $(P<0.05)$ expression of DEFB5 and DEFB 7 but decreased $(P<0.05)$ expression of $L A P$ in MEC in the absence of LPS stimulation (Figure 1A, Supplemental Table S2). As expected, LPS also increased ( $P$ $<0.05)$ the expression of $C C L 5, I L-1 \beta, I L 8$, and $i N O S$ (Figure 1A), and $1,25(\mathrm{OH})_{2} \mathrm{D}_{3}$ increased $(P<0.001)$ CYP24A1, iNOS, and S100A12 (Figure 1A). In fibroblasts, only transcripts for $L A P$ were detected for the $\beta$-defensins (Figure 1B). The LPS treatment increased $(P=0.04) L A P$ expression in fibroblasts in addition to potent induction of $C C L 5, I L-1 \beta$, and $I L 8$ (Figure 1B, Supplemental Table S2). The $1,25(\mathrm{OH})_{2} \mathrm{D}_{3}$ treatment also drastically increased $(P<0.001)$ CYP24A1 and, in the presence of LPS, increased $(P=0.003)$ $i N O S$ in fibroblasts (Figure 1B, Supplemental Table S2) indicating that vitamin D signaling was functional in fibroblasts.

Treatment of MEC with the DNA methyltransferase inhibitor 5 -Aza increased $(P<0.05)$ expression of each $\beta$-defensin gene except $E B D$ (Figure 2A, Supplemental Table S3). Furthermore, DEFB4, DEFB5, DEFB\%, $D E F B 10, L A P$, and TAP were increased $(P<0.05)$ in MEC treated with the combination of LPS and 5-Aza compared with either treatment alone (Figure 2A). The 5 -Aza treatment also increased $(P<0.05)$ expression of CCL5, IL1B, IL8, iNOS, and S100A12, and the interaction between LPS and 5-Aza was significant $(P<$ 0.05 ) for all genes except DEFB4, CYP24A1, and $i N O S$ such that the change in response to LPS was greater in the absence of 5-Aza treatment compared with the presence of 5-Aza (Figure 2A, Supplemental Table S3). Treatment of MEC with 5-Aza did not affect induction of IL1B, IL8, CYP24A1, or $i N O S$ by $1,25(\mathrm{OH})_{2} \mathrm{D}_{3}$ (Figure 2B, Supplemental Table S3). Similar to the effect in MEC, 5-Aza treatment of fibroblasts increased $(P<$ 0.05 ) expression of $L A P, C C L 5$, and $I L 8$; however, the interaction between LPS and 5-Aza was only significant $(P=0.02)$ for $L A P$ such that it was further increased by the combination of LPS and 5-Aza (Supplemental Table S3). Transcripts for $I L 1 B$ and $i N O S$ in fibroblasts were not affected by 5 -Aza treatment, and the $\beta$-defensins were not detectable in fibroblasts treated with 5-Aza.

Unlike 5-Aza, treatment of MEC with the histone deacetylase inhibitor TSA decreased $(P<0.05)$ LPSinduced expression of the most abundant defensins, LAP and TAP (Figure 3A, Supplemental Table S4). Treatment of MEC with TSA increased $(P<0.05)$ $D E F B 7, D E F B 10$, and $I L 8$; however, the interaction between LPS and TSA was significant for DEFB3, DEFB 4, DEFB5, DEFB7, IL1 $\beta$, and IL8 such that TSA increased expression in the absence of LPS but not in the presence of LPS (Figure 3A, Supplemental Table S4). In the case of $1,25(\mathrm{OH})_{2} \mathrm{D}_{3}$ and TSA, each treatment alone increased $D E F B \%$ and the combination of the 2 treatments resulted in greater $D E F B 7$ expression compared with either treatment alone (Figure 3A, Supplemental Table S4). In contrast, the interaction between $1,25(\mathrm{OH})_{2} \mathrm{D}_{3}$ and TSA was significant for $L A P, E B D$, and $I L 8$. In the case of $L A P$ and $E B D$, the 2 treatments combined abolished the negative effects of either treatment alone; whereas, IL8 was increased by the combination of $1,25(\mathrm{OH})_{2} \mathrm{D}_{3}$ and TSA (Figure 3A, Supplemental Table S4). The TSA treatment did not affect $L A P$ in fibroblasts, but increased $(P<0.05)$ $I L 1 B$ and IL8 (Supplemental Table S4).

The presence of NF-kB binding sites in proximal promoter regions of $\beta$-defensin genes are deemed responsible for induction of $\beta$-defensin expression in response to LPS stimulation (Yang et al., 2006). Yet, although LPS was a major driver of $\beta$-defensin expression in MEC in this experiment, only $L A P$ was detectable in fibroblasts and induction by LPS in fibroblasts was 
minor compared with that in MEC. The major discrepancy in $\beta$-defensin expression between the 2 cell types, both of which displayed robust responses of several key cytokines, is likely explained by the greater accessibility of the $\beta$-defensin gene region in MEC compared with fibroblasts. Indeed, Liu et al. (2011) showed that chromatin compaction prevents expression of $L A P$. Inhibition of DNA methyltransferase and histone deacetylase activities promotes an open chromatin state, and in this study treatment with inhibitors of those enzyme activities increased $\beta$-defensin expression in MEC.
Thus, exploration of factors (i.e., nutritional or environmental) that contribute to chromatin accessibility in regulatory regions of $\beta$-defensin genes may result in ways to enhance $\beta$-defensin expression in the udder.

The increased expression of $\beta$-defensins in response to treatment with the inhibitors is not likely a result of increased NF- $\kappa \mathrm{B}$ activity as indicated by the interactions between LPS and the inhibitors. Rather, the effects of LPS in some cases were diminished by the 5-Aza and TSA treatments. For example, although the combined effects of LPS and 5-Aza resulted in the greatest ex-

\section{A) Mammary Epithelial Cells}

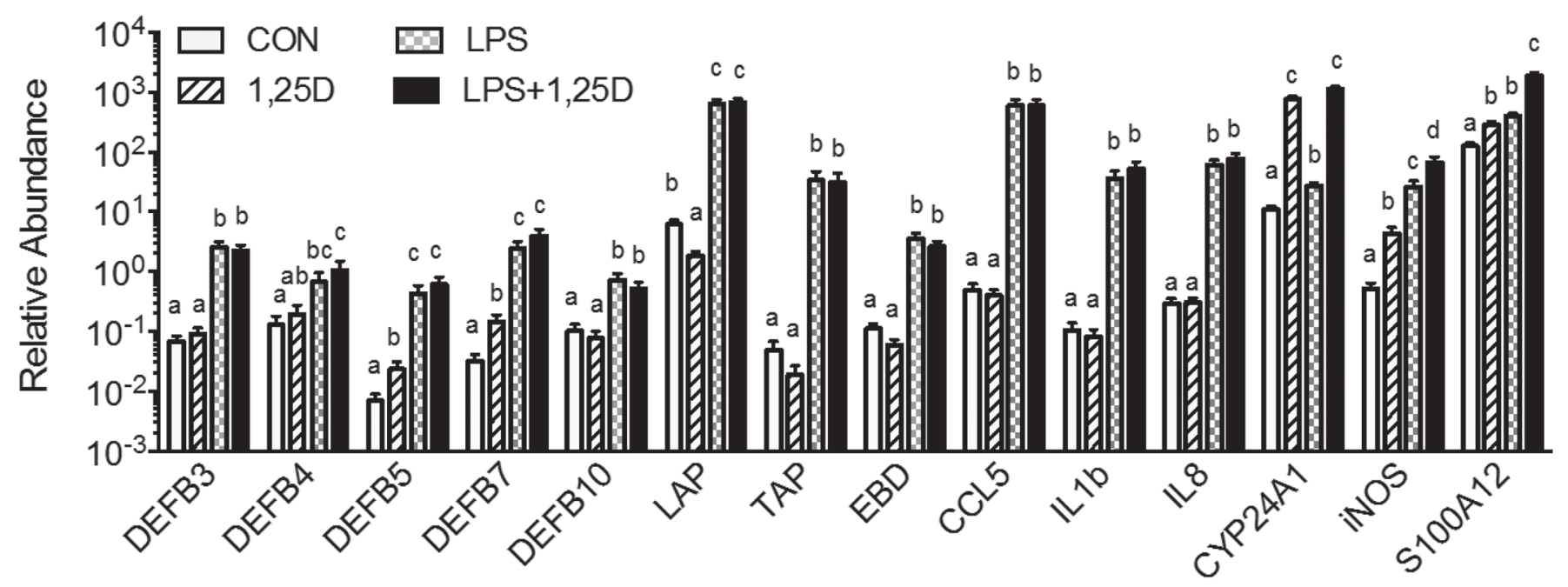

\section{B) Dermal Fibroblasts}

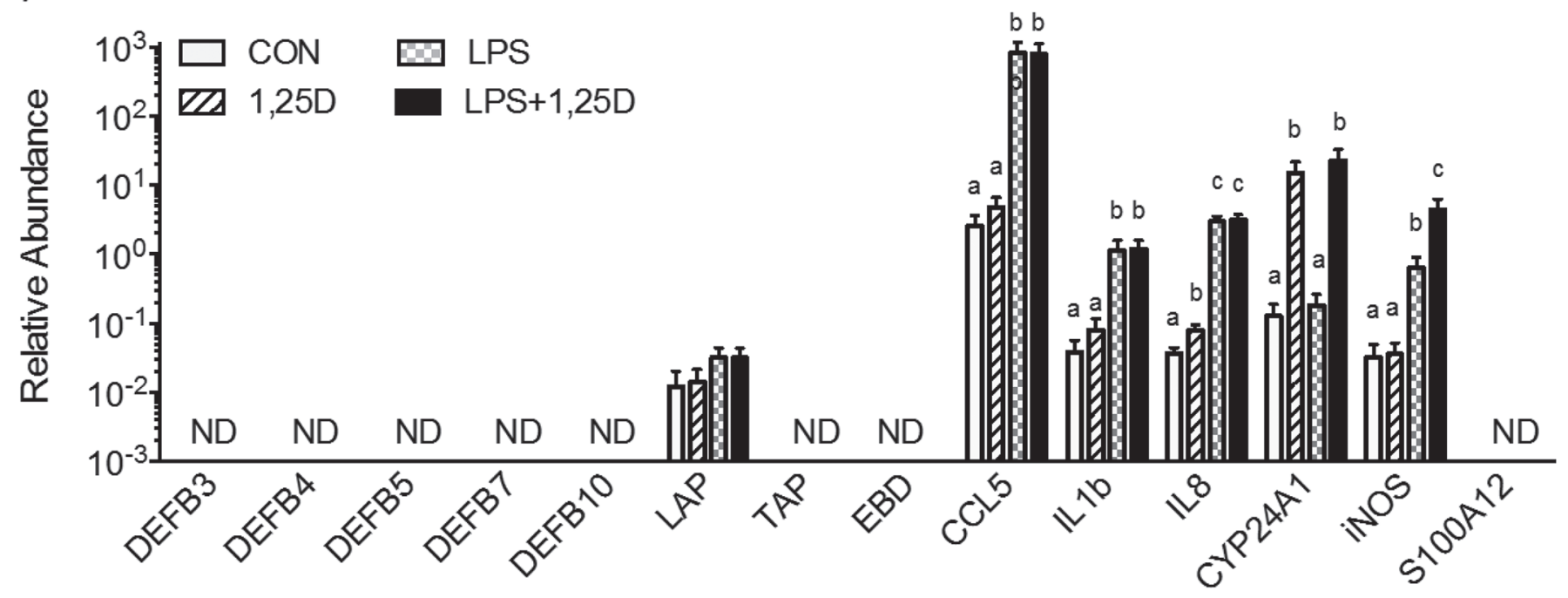

Figure 1. Effects of LPS (0 or $100 \mathrm{ng} / \mathrm{mL})$ and 1,25-dihydroxyvitamin $\mathrm{D}_{3}(1,25 \mathrm{D}, 0 \mathrm{or} 4 \mathrm{ng} / \mathrm{mL})$ on gene expression in (A) mammary epithelial cells and $(B)$ dermal fibroblasts. Data represent least squares means $\pm \mathrm{SEM}$ abundance of transcripts for $\beta$-defensin $(D E F B) 3, D E F B 4$, $D E F B 5, D E F B \%, D E F B 10$, enteric $\beta$-defensin $(E B D)$, lingual antimicrobial peptide $(L A P)$, tracheal antimicrobial peptide ( TAP), chemokine (C-C motif) ligand $5(C C L 5)$, IL-1 $\beta(I L 1 B)$, IL-8 $(I L 8)$, vitamin D 24-hydroxylase $(C Y P 24 A 1)$, inducible nitric oxide synthase $(i N O S)$, and S100 calcium binding protein A12 (S100A12). ND = transcript not detected. Transcript abundances are expressed relative to geometric mean of $A C T B, G A P D H$, and $R P S 9$. Means with different letters (a-d) are different, $P<0.05$. Main effects of LPS and $1,25(\mathrm{OH}){ }_{2} \mathrm{D}_{3}$ and interactions between treatments are reported in Supplemental Table S2 (https://doi.org/10.3168/jds.2018-16141). 


\section{A) LPS $\times$ 5-Aza}

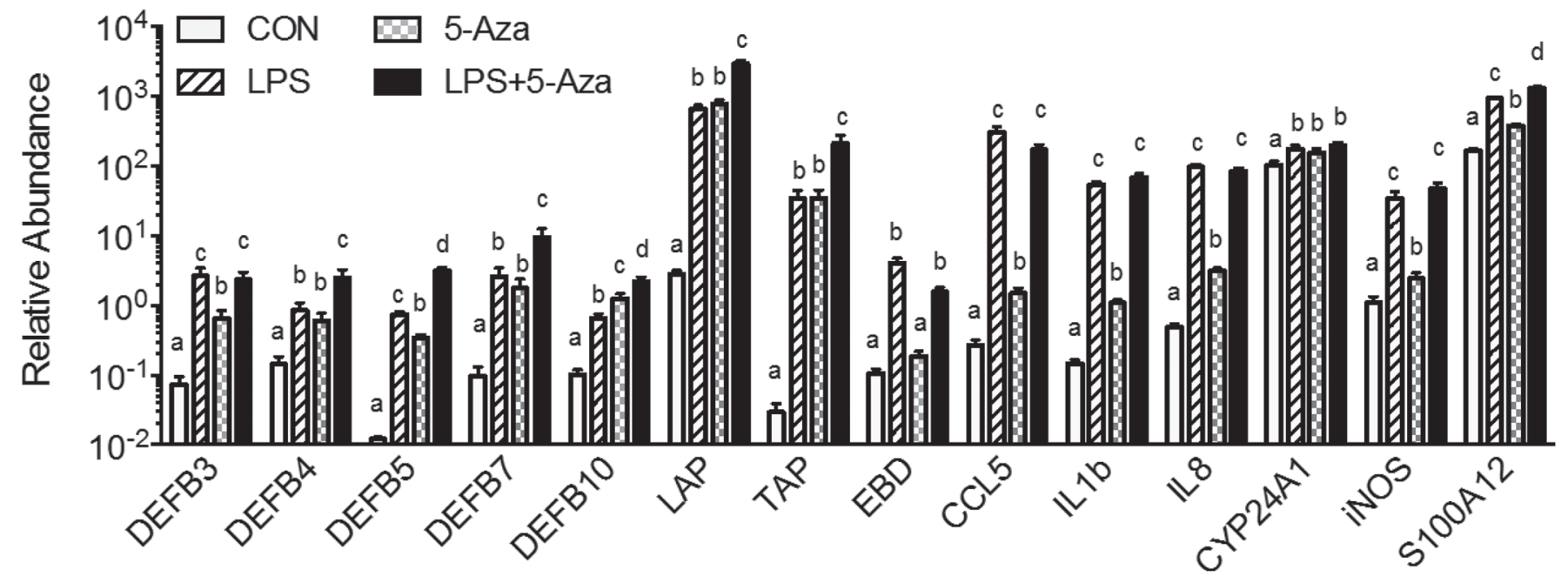

B) $1,25(\mathrm{OH})_{2} \mathrm{D}_{3} \times 5-\mathrm{Aza}$

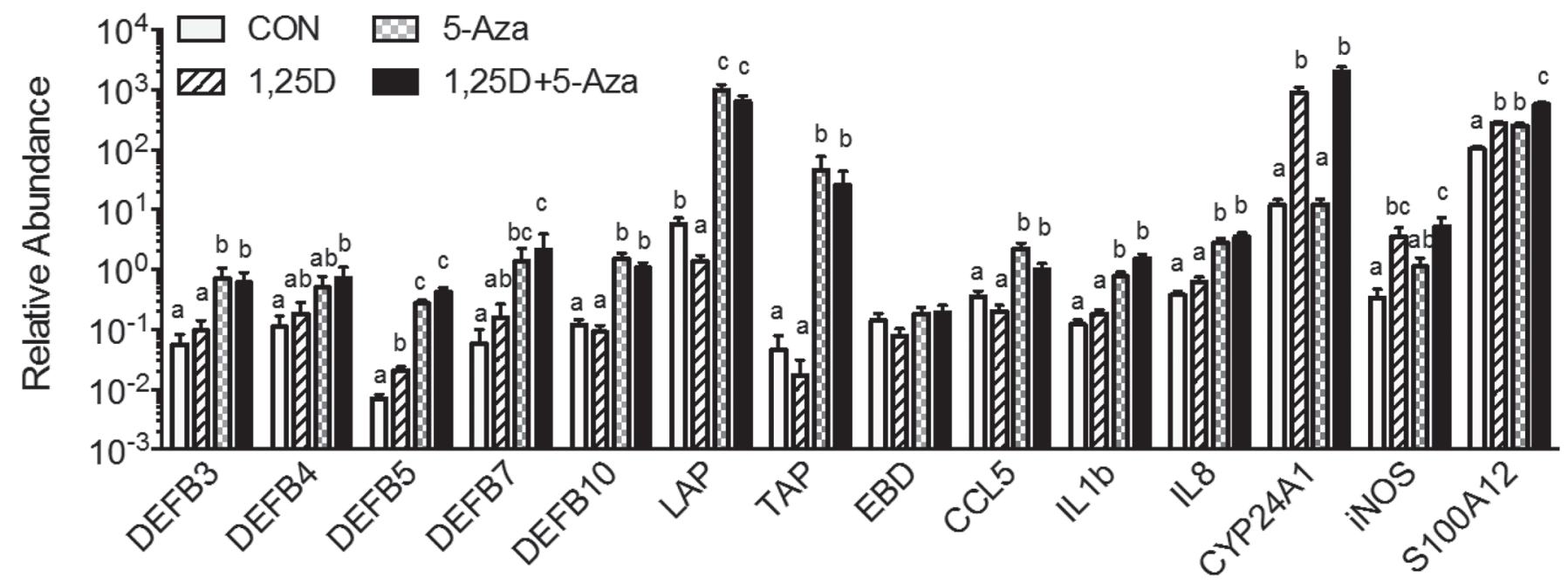

Figure 2. Effects of DNA methylation inhibitor, 5-aza-2'-deoxycytidine (5-Aza, 0 or $5 \mu M$ ) in combination with (A) LPS (0 or 100 ng/ $\mathrm{mL}$ ) or (B) 1,25-dihydroxyvitamin $\mathrm{D}_{3}\left[1,25(\mathrm{OH})_{2} \mathrm{D}_{3}, 0\right.$ or $\left.4 \mathrm{ng} / \mathrm{mL}\right]$ on $\beta$-defensin expression in mammary epithelial cells. Data represent least squares means \pm SEM abundance of transcripts for $\beta$-defensin $(D E F B) 3, D E F B 4, D E F B 5, D E F B 7, D E F B 10$, enteric $\beta$-defensin $(E B D)$, lingual antimicrobial peptide $(L A P)$, tracheal antimicrobial peptide (TAP), chemokine (C-C motif) ligand 5 (CCL5), IL-1 $($ IL1B), IL-8 (IL8), vitamin D 24-hydroxylase (CYP24A1), inducible nitric oxide synthase (iNOS), and S100 calcium binding protein A12 (S100A12) in mammary epithelial cells. Transcript abundances expressed relative to geometric mean of $A C T B, G A P D H$, and RPS9. Means with different letters (a-d) are different, $P<0.05$. Main effects of 5-Aza and interactions between treatments are reported in Supplemental Table S3 (https://doi.org/10.3168/jds 2018-16141).

pression of $\beta$-defensins in MEC, 5 -Aza did not increase the effects of LPS on the $\beta$-defensins. In addition, TSA treatment decreased abundance of $L A P$ and TAP of MEC treated with LPS compared with MEC treated with LPS alone. Similar patterns were observed for the cytokines that were induced by LPS. Therefore, the inhibitors did not seem to increase $\beta$-defensin expression via NF- $\kappa B$ signaling, the main driver of $\beta$-defensin expression. However, testing of just one dose and one duration of treatments, as done in these experiments, limits the extent to which the results can be interpreted.

Vitamin D signaling is a major inducer of several $\beta$-defensins (DEFB3, DEFB 4, DEFB 7, and DEFB10) in bovine monocytes (Merriman et al., 2015), but it only increased $D E F B 5$ and $D E F B 7$ in MEC. Although direct induction of $\beta$-defensin expression by binding of the vitamin $\mathrm{D}$ receptor to $\beta$-defensin promoters is unlikely (Merriman et al., 2015), we hypothesized that inhibition 


\section{A) LPS $\times$ TSA}

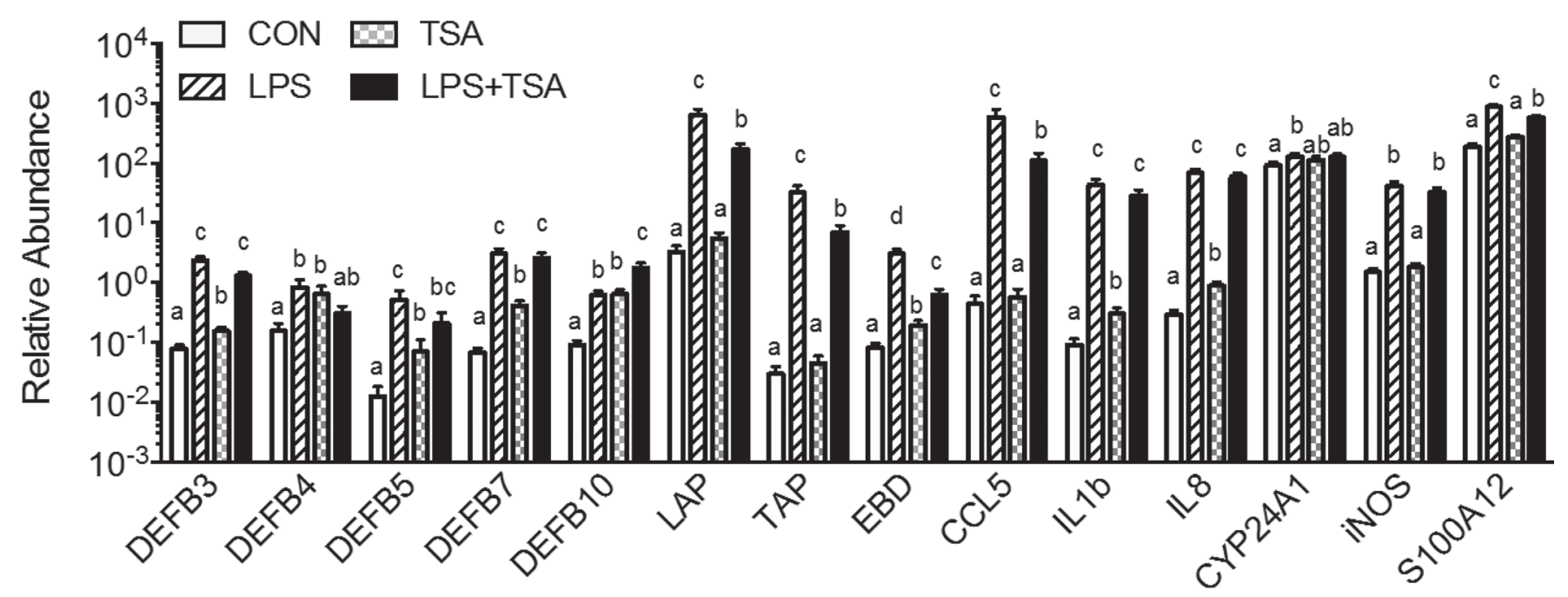

B) $1,25(\mathrm{OH})_{2} \mathrm{D}_{3} \times \mathrm{TSA}$

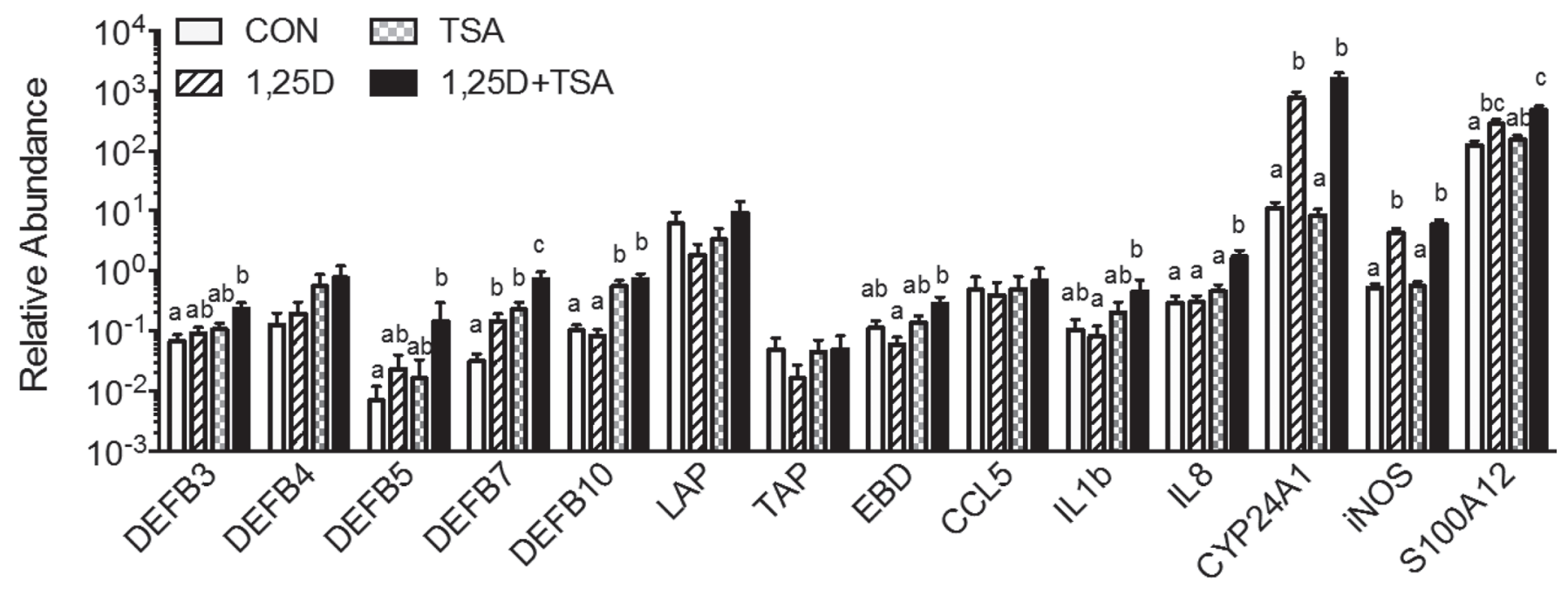

Figure 3. Effects of histone deacetylase inhibitor, trichostatin A (TSA), in combination with (A) LPS or (B) 1,25-dihydroxyvitamin $\mathrm{D}_{3}$ $\left[1,25(\mathrm{OH})_{2} \mathrm{D}_{3}\right]$ on $\beta$-defensin expression in mammary epithelial cells. Data represent least squares means \pm SEM abundance of transcripts for $\beta$-defensin $(D E F B) 3, D E F B 4, D E F B 5, D E F B$ 7, $D E F B 10$, enteric $\beta$-defensin $(E B D)$, lingual antimicrobial peptide $(L A P)$, tracheal antimicrobial peptide (TAP), chemokine (C-C motif) ligand 5 (CCL5), IL-1 3 (IL1B), IL-8 (IL8), vitamin D 24-hydroxylase (CYP24A1), inducible nitric oxide synthase (iNOS), and S100 calcium binding protein A12 (S100A12) in mammary epithelial cells. Transcript abundances expressed relative to geometric mean of $A C T B, G A P D H$, and $R P S 9$. Means with different letters (a-d) are different, $P<0.05$. Main effects of TSA and interactions between treatments are reported in Supplemental Table S4 (https://doi.org/10.3168/jds.2018-16141).

of DNA methylation or histone deacetylation would result in increased expression of $D E F B 3, D E F B 4, D E F B$, and $D E F B 10$ in response to $1,25(\mathrm{OH})_{2} \mathrm{D}_{3}$ treatment. Interactions between $1,25(\mathrm{OH})_{2} \mathrm{D}_{3}$ and 5 -Aza or TSA, however, were not significant for expression of $D E F B 3$, $D E F B 4, D E F B 7$, and $D E F B 10$, indicating that factors other than chromatin remodeling (i.e., transcription factors) are more important for induction of $\beta$-defensin genes by $1,25(\mathrm{OH})_{2} \mathrm{D}_{3}$ in bovine monocytes. In contrast, the interactions between $1,25(\mathrm{OH})_{2} \mathrm{D}_{3}$ and LPS, 5-Aza, or TSA were significant for $L A P$ expression, which was downregulated by $1,25(\mathrm{OH})_{2} \mathrm{D}_{3}$ treatment alone, but negative effects of $1,25(\mathrm{OH})_{2} \mathrm{D}_{3}$ were largely reversed by effects of LPS or inhibitor. Taken together, these data indicate that vitamin $\mathrm{D}$ signaling is not a major contributor to $\beta$-defensin expression in MEC. In comparison, $1,25(\mathrm{OH})_{2} \mathrm{D}_{3}$ strongly upregulated $i N O S$ and S100A12 in MEC, which both contribute significantly to the innate immune response of the udder.

In conclusion, DNA methylation and histone deacetylation seem to contribute significantly to $\beta$-defensin expression in bovine MEC. Identification of key regions 
of DNA methylation and histone acetylation of the bovine chromosome $27 \beta$-defensin cluster and the factors that contribute to the epigenetic status of those regions has significant implications for defense of the mammary gland. Nutrition and environmental factors, such as pathogen exposure, early in life can lead to epigenetic modifications that shape innate immunity. For instance, in utero exposure to LPS resulted in greater $\beta$-defensin expression in neutrophils of heifers (Carroll et al., 2017). Better knowledge of how nutritional and environmental factors affect remodeling of chromatin in the $\beta$-defensin region will hopefully lead to management or therapeutic strategies that improve resistance to intramammary infections in dairy cattle.

\section{ACKNOWLEDGMENTS}

This work was supported with funds from USDA (Washington, DC) Hatch Project FLA-ANS-005309 through the University of Florida Institute of Food and Agricultural Sciences and funds from the Southeast Milk Inc. Milk Checkoff Research and Promotion Board (Belleview, FL).

\section{REFERENCES}

Alva-Murillo, N., I. Medina-Estrada, M. Báez-Magaña, A. Ochoa-Zarzosa, and J. E. López-Meza. 2015. The activation of the TLR2/p38 pathway by sodium butyrate in bovine mammary epithelial cells is involved in the reduction of Staphylococcus aureus internalization. Mol. Immunol. 68(2 Pt B):445-455.

Carroll, J. A., N. C. Burdick Sanchez, J. D. Arthingon, C. D. Nelson, A. L. Benjamin, F. T. Korkmaz, D. E. Kerr, and P. A. Lancaster. 2017. In utero exposure to LPS alters the postnatal acute-phase response in beef heifers. Innate Immun. 23:97-108.

Diamond, G., M. Zasloff, H. Eck, M. Brasseur, W. L. Maloy, and C. L. Bevins. 1991. Tracheal antimicrobial peptide, a cysteine-rich peptide from mammalian tracheal mucosa: Peptide isolation and cloning of a cDNA. Proc. Natl. Acad. Sci. USA 88:3952-3956.

Ganz, T. 2003. Defensins: Antimicrobial peptides of innate immunity. Nat. Rev. Immunol. 3:710-720.

Green, B. B., and D. E. Kerr. 2014. Epigenetic contribution to individual variation in response to lipopolysaccharide in bovine dermal fibroblasts. Vet. Immunol. Immunopathol. 157:49-58.

Isobe, N., K. Morimoto, J. Nakamura, A. Yamasaki, and Y. Yoshimura. 2009. Intramammary challenge of lipopolysaccharide stimulates secretion of lingual antimicrobial peptide into milk of dairy cows. J. Dairy Sci. 92:6046-6051.
Liu, S., X. Shi, I. Bauer, J. Günther, and H. M. Seyfert. 2011. Lingual antimicrobial peptide and IL-8 expression are oppositely regulated by the antagonistic effects of NF- $\kappa \mathrm{B}$ p65 and $\mathrm{C} / \mathrm{EBP} \beta$ in mammary epithelial cells. Mol. Immunol. 48:895-908.

Livak, K. J., and T. D. Schmittgen. 2001. Analysis of relative gene expression data using real-time quantitative PCR and the 2(-Delta Delta C(T)). Methods 25:402-408.

Mackenzie-Dyck, S., S. Attah-Poku, V. Juillard, L. A. Babiuk, and S. van Drunen Littel-van den Hurk. 2011. The synthetic peptides bovine enteric $\beta$-defensin (EBD), bovine neutrophil $\beta$-defensin (BNBD) 9 and BNBD 3 are chemotactic for immature bovine dendritic cells. Vet. Immunol. Immunopathol. 143:87-107.

Meade, K. G., P. Cormican, F. Narciandi, A. Lloyd, and C. O'Farrelly. 2014. Bovine beta-defensin gene family: Opportunities to improve animal health? Physiol. Genomics 46:17-28.

Merriman, K. E., M. F. Kweh, J. L. Powell, J. D. Lippolis, and C. D. Nelson. 2015. Multiple $\beta$-defensin genes are upregulated by the vitamin D pathway in cattle. J. Steroid Biochem. Mol. Biol. 154:120-129.

Merriman, K. E., J. L. Powell, J. E. P. Santos, and C. D. Nelson. 2018. Intramammary 25-hydroxyvitamin D3 modulates innate immune responses to endotoxin-induced mastitis. J. Dairy Sci. 101:75937607.

Pike, J. W., and M. B. Meyer. 2014. Fundamentals of vitamin D hormone-regulated gene expression. J. Steroid Biochem. Mol. Biol. 144(Pt A):5-11.

Roosen, S., K. Exner, S. Paul, J. M. Schroder, E. Kalm, and C. Looft. 2004. Bovine beta-defensins: Identification and characterization of novel bovine beta-defensin genes and their expression in mammary gland tissue. Mamm. Genome 15:834-842.

Schonwetter, B. S., E. D. Stolzenberg, and M. A. Zasloff. 1995. Epithelial antibiotics induced at sites of inflammation. Science 267:16451648 .

Selsted, M. E., Y. Q. Tang, W. L. Morris, P. A. McGuire, M. J. Novotny, W. Smith, A. H. Henschen, and J. S. Cullor. 1993. Purification, primary structures, and antibacterial activities of beta-defensins, a new family of antimicrobial peptides from bovine neutrophils. J. Biol. Chem. 268:6641-6648.

Swanson, K., S. Gorodetsky, L. Good, S. Davis, D. Musgrave, K. Stelwagen, V. Farr, and A. Molenaar. 2004. Expression of a beta-defensin mRNA, lingual antimicrobial peptide, in bovine mammary epithelial tissue is induced by mastitis. Infect. Immun. 72:73117314.

Téllez-Pérez, A. D., N. Alva-Murillo, A. Ochoa-Zarzosa, and J. E. López-Meza. 2012. Cholecalciferol (vitamin D) differentially regulates antimicrobial peptide expression in bovine mammary epithelial cells: Implications during Staphylococcus aureus internalization. Vet. Microbiol. 160:91-98.

Wohlgemuth, S. E., Y. Ramirez-Lee, S. Tao, A. P. A. Monteiro, B. M. Ahmed, and G. E. Dahl. 2016. Short communication: Effect of heat stress on markers of autophagy in the mammary gland during the dry period. J. Dairy Sci. 99:4875-4880.

Yang, W., A. Molenaar, B. Kurts-Ebert, and H. M. Seyfert. 2006. NF-kappaB factors are essential, but not the switch, for pathogenrelated induction of the bovine beta-defensin 5-encoding gene in mammary epithelial cells. Mol. Immunol. 43:210-225. 